\title{
Endoscopic Yield in Anemia of Chronic Disease:A Single-Center Retrospective Study of U.S. Veteran Population
}

\author{
Brian V Dinh ${ }^{1, *}$, We'Am Hussain ${ }^{2}$, Christopher A Chan², Ronald J Markert², and Padmini Krishnamurthy ${ }^{1,3}$ \\ ${ }^{1}$ Department of Gastroenterology, Wright State University, Dayton, Ohio, USA \\ ${ }^{2}$ Department of Internal Medicine, Wright State University, Dayton, Ohio, USA \\ ${ }^{3}$ Dayton Veterans Affairs, Division of Gastroenterology, Wright State University, Dayton, Ohio, USA
}

*Corresponding author: Brian V Dinh, MD, Gastroenterologist, Department of Gastroenterology, Wright State University, Dayton, Ohio, USA, E-mail: dinhbv317@gmail.com

Received: 22 Jan, 2021 | Accepted: 17 Mar, 2021 | Published: 23 Mar, 2021

Citation: Dinh BV, Hussain W, Chan CA, Markert RJ, Krishnamurthy P (2021) Endoscopic Yield in Anemia of Chronic Disease: A Single-Center Retrospective Study of U.S. Veteran Population. Clin Res Open Access 7(1): dx.doi.org/10.16966/2469-6714.164

Copyright: (C) 2021 Dinh BV, et al. This is an open-access article distributed under the terms of the Creative Commons Attribution License, which permits unrestricted use, distribution, and reproduction in any medium, provided the original author and source are credited.

\section{Abstract}

Goals: The aim of the study was to evaluate endoscopic yield in patients with Anemia of Chronic Disease (ACD) who had no Gastrointestinal (GI) symptoms. We analyzed the impact of laboratory and clinical variables on endoscopic yield in this cohort.

Background: Iron Deficiency Anemia (IDA) is a known indication for endoscopy to rule out GI source of blood loss. There are no established guidelines for endoscopy in patients with ACD who do not have GI symptoms leading to unnecessary investigations and overutilization of health care resources and costs.

Study: We conducted a single-center retrospective study in the U.S. veteran population who underwent Esophagogastroduodenoscopy (EGD) or colonoscopy for anemia between January 2010 and December 2018. We categorized patients into IDA, ACD, or Mixed Anemia (MA) based on serum ferritin levels of $\leq 30 \mathrm{ng} / \mathrm{ml}, 30-100 \mathrm{ng} / \mathrm{ml}$, and $>100 \mathrm{ng} / \mathrm{ml}$, respectively, and evaluated endoscopic yield and clinical variables.

Results: Of 1162 patients who underwent EGD and/or colonoscopy for anemia, 82 patients who did not have any Gl symptoms underwent endoscopy for indication of ACD. Endoscopic yield was 50\% for EGD and 11\% for colonoscopy. Degree of anemia, mean corpuscular volume, ferritin, and use of antiplatelet and/or anticoagulant agents and Non-Steroidal Anti-Inflammatory Drugs (NSAIDs) did not have an impact on endoscopic yield.

Conclusion: Our study suggests that EGD may be beneficial for evaluation of all patients with ACD without GI symptoms, regardless of underlying lab or clinical findings. Due to limited yield of colonoscopy in patients with ACD, colonoscopy should be performed on a case-by-case basis.

Keywords: Anemia of chronic disease; Endoscopic yield; Anemia

\section{Introduction}

Anemia is broadly defined as abnormally low Hemoglobin $(\mathrm{Hb})$, with an $\mathrm{Hb}$ of $\leq 12 \mathrm{mg} / \mathrm{dl}$ in women and $\leq 13 \mathrm{mg} / \mathrm{dl}$ in men [1-3]. The two most common causes of chronic anemia in the world are Iron Deficiency Anemia (IDA) and Anemia of Chronic Disease (ACD) [25]. In some cases, concomitant IDA and ACD may be present and better characterized as a Mixed Anemia (MA).

Categorizing chronic anemia into IDA, ACD and MA can be challenging as the definitions have varied among studies, and precise cutoffs are laboratory dependent [2,6,7]. Many patients may have a combination of IDA and ACD, falling into the category of MA $[5,8,9]$. A serum ferritin of $<30 \mathrm{ng} / \mathrm{ml}$ is suggestive of iron deficiency anemia [6]. Conversely, a serum ferritin of $>100 \mathrm{ng} /$ $\mathrm{ml}$ makes a diagnosis of iron deficiency unlikely and suggestive of ACD $[8,10,11]$.

Iron deficiency anemia is an established indication for endoscopy to rule out a Gastrointestinal (GI) source of occult blood loss. Endoscopy methods, such as Esophagogastroduodenoscopy (EGD), colonoscopy, and Video Capsule Endoscopy (VCE), are performed in isolation or in combination to evaluate the cause of anemia. Previous studies have found that the diagnostic yield for IDA ranges from $18 \%$ to $41 \%$ for EGD and $6 \%$ to $37 \%$ for colonoscopy [12-17].

Diagnostic yield of VCE ranges from $26 \%$ to $66 \%$ in unexplained IDA, defined as anemia without findings on EGD or colonoscopy $[2,18,19]$. To date, there are few recommendations regarding the utility of endoscopy in ACD.

Performing endoscopy on all patients with ACD, in the absence of GI symptoms, may result in overutilization of resources and increased health care costs. In a United Kingdom study, Powell $\mathrm{N}$, et al. [20] found higher endoscopic yield in those with serum ferritin $\leq 30 \mathrm{ng} / \mathrm{ml}$ compared to those $>100 \mathrm{ng} / \mathrm{ml}$, but a similar yield when comparing serum ferritin $\leq 30 \mathrm{ng} / \mathrm{ml}$ and between 30 $\mathrm{ng} / \mathrm{ml}$ and $100 \mathrm{ng} / \mathrm{ml}$.

The aim of the study was to evaluate endoscopic yield and determine variables that increase endoscopic yield in patients with ACD as there is limited data on the utility of endoscopy for ACD. 


\section{Methods}

We conducted a single center retrospective study at the Gastroenterology Department of the Veterans Affairs Medical Center (VAMC) in Dayton, Ohio after obtaining approval from the Wright State University Institutional Review Board. Using ICD-9 and ICD-10 codes, chart review was performed using electronic health records and Endosoft, a computerized database for storage of endoscopic reports. Consecutive patients who underwent endoscopy for anemia between January 2010 and December 2018 were included.

Men with $\mathrm{Hb}<13 \mathrm{~g} / \mathrm{dl}$ and women with $\mathrm{Hb}<12 \mathrm{~g} / \mathrm{dl}$ were included in the study and classified into IDA, MA and ACD based on serum ferritin $\leq 30 \mathrm{ng} / \mathrm{ml}, 30-100 \mathrm{ng} / \mathrm{ml}$, and $>100 \mathrm{ng} / \mathrm{ml}$, respectively. To account for scheduling delays, the value for ferritin utilized was the lowest recorded within 3 months preceding the date of endoscopy. Laboratory data for $\mathrm{Hb}, \mathrm{Fe} \mathrm{Sat} \%$, serum ferritin, and Mean Corpuscular Volume (MCV) were within six months prior to endoscopy. Wanting to avoid clinical situations where endoscopy was imperative regardless of the patient's anemia status, our exclusion criteria included:

1. Overt gastrointestinal bleed within six months of endoscopy

2. Active gastrointestinal cancer with planned or undergoing treatment

3. Incomplete iron studies within six months of endoscopy

4. Incomplete or poor prep for endoscopy

5. Incomplete records or test results

6. Events after the sentinel consult for anemia

7. Serum ferritin $<100 \mathrm{ng} / \mathrm{ml}$

Further patient data collected included were age at time of endoscopy, gender, race, use of antiplatelet and/or anticoagulant agents within 6 months of endoscopy, and use of Non-Steroidal AntiInflammatory Drugs (NSAIDs).

Endoscopic data collected were findings reported on esophagogastroduodenoscopy and colonoscopy. Reflecting routine clinical practice, some patients underwent both EGD and colonoscopy and some only one of the procedures depending on clinical assessment by the treating physician, patient's symptoms, and patient's wishes. Findings were considered significant on EGD and colonoscopy if they were thought to be causing occult GI blood loss. These were determined based on known common acceptable causes of anemia. For EGD, significant findings were Arteriovenous Malformation (AVM), erosive esophagitis of any grade, hemorrhagic gastritis, gastric and/or duodenal erosions, Cameron erosions, malignancy, peptic ulcer disease, celiac disease, Gastric Antral Vascular Ectasia (GAVE), portal gastropathy, polyps $>2 \mathrm{~cm}$, and submucosal mass. Non-significant findings included hiatal hernia without Cameron erosions, Barrett's esophagus, esophageal varices, incidental duodenal polyps $<2 \mathrm{~cm}$, and fundic polyps. Significant findings for colonoscopy were polyp $>2 \mathrm{~cm}, \mathrm{AVM}$, colitis of any etiology including Inflammatory Bowel Disease (IBD), NSAIDs, microscopic, ischemic, radiation or infectious colitis, ileal ulcers, malignancy, and colorectal ulcers. Non-significant findings included internal or external hemorrhoids, polyps $<2 \mathrm{~cm}$, and diverticulosis. Biopsy results from the endoscopic procedures were reviewed to corroborate endoscopic findings and diagnosis when necessary.

The primary outcome was endoscopic yield, which was calculated by dividing the number of patients with one or more significant findings by the total number of patients who underwent EGD or colonoscopy, reported separately. We did not include findings of video capsule endoscopy as less than $4 \%$ of our patients underwent VCE for ACD. Additionally, we evaluated variables that may impact endoscopic yield in patients with $\mathrm{ACD}$, i.e., age, race, laboratory parameters, and use of NSAIDs and anti-platelet and anticoagulant agents.

Statistical analysis was conducted using IBM SPSS Statistics 25.0 (IBM, Armonk, NY). Means and standard deviations are reported for continuous variables and counts and percentages for categorical variables. The chi square test was used to compare two variables measured on a categorical scale. Inferences were made at the 0.05 level of significance with no corrections for multiple comparisons.

\section{Results}

A total of 1162 patients underwent endoscopy between January 2010 and December 2018 for indication of anemia. Of these, 366 patients were excluded due to inadequate information on iron studies. For the remaining 796 patients, 426 (53.5\%) underwent endoscopy for IDA, 164 (14.1\%) for MA and 206 (32.4\%) for ACD. Of the 206 patients with ACD, 82 met the inclusion criteria.

Table 1 showed the baseline characteristics of the cohort. The mean age was $66 \pm 9$ and $96.3 \%$ men. Based on ethnicity, Caucasians accounted for $67.1 \%$ and African Americans accounted for $32.9 \%$. Anti-platelet and/or anticoagulant medications were used by $30.5 \%$, and NSAIDs were used by $9.8 \%$ of patients. The mean hemoglobin concentration was $9.57 \pm 2.2 \mathrm{gm} / \mathrm{dl}$, ferritin was $393.13 \pm 508.21 \mathrm{ng} /$ $\mathrm{ml}, \mathrm{Fe}$ Sat $\%$ was $19.89 \pm 11.82 \%$, and MCV was $87.21 \pm 7.51 \mathrm{fL}$.

The endoscopic yield for EGD was $50 \%$ and for colonoscopy was $11 \%$. Tables 2 and 3 showed the significant findings for EGD and colonoscopy. The most frequent significant findings on EGD were gastric and/or duodenal erosion $(37.8 \%, \mathrm{n}=14)$, peptic ulcer disease (24.4\%, n=9), AVM (13.3\%, $n=5)$, and erosive esophagitis $(10.9 \%$, $\mathrm{n}=4$ ), with gastric cancer, portal gastropathy, hemorrhagic gastritis, and large polyp combined accounting for $13.6 \%(n=5)$ of lesions. Gastric cancer was found in one patient. The frequency of significant findings on colonoscopy were large polyps $>2 \mathrm{~cm}(42.8 \%, \mathrm{n}=3)$, colorectal cancer $(28.6 \%, \mathrm{n}=2), \operatorname{AVM}(14.3 \%, \mathrm{n}=1)$, and colo-ileal ulcers $(14.3 \%, \mathrm{n}=1)$.

Table 1: Baseline characteristics of 82 patients with anemia of chronic disease.

\begin{tabular}{|c|c|c|}
\hline \multicolumn{2}{|c|}{ Characteristic } & $\begin{array}{c}\text { Total } \\
\text { Patients }=82\end{array}$ \\
\hline \multicolumn{2}{|l|}{ Mean Age } & $66 \pm 9$ \\
\hline \multicolumn{2}{|l|}{ Sex male, $n$ (\%) } & $79(96.3)$ \\
\hline \multirow{2}{*}{ Race } & Caucasian & $55(67.1)$ \\
\hline & African American & 27 (32.9) \\
\hline \multicolumn{2}{|l|}{ Mean $\mathrm{Hb}$ (gm/dl) } & $9.57 \pm 2.2$ \\
\hline \multicolumn{2}{|l|}{ Mean Serum Ferritin (ng/ml) } & $393.13 \pm 508.21$ \\
\hline \multirow{2}{*}{$\begin{array}{l}\text { Number of patients based on } \\
\text { Ferritin, } \mathrm{ng} / \mathrm{ml}[\mathrm{n}(\%)]\end{array}$} & 101-499 & $68(82.7)$ \\
\hline & $\geq 500$ & $14(17.3)$ \\
\hline \multicolumn{2}{|l|}{ Mean MCV fL/red cells } & $87.2 \pm 7.5$ \\
\hline \multicolumn{2}{|l|}{ Mean Fe Sat\% } & $19.9 \pm 11.8$ \\
\hline \multicolumn{2}{|c|}{$\begin{array}{l}\text { Number of patients on antiplatelets/anticoagulants } \\
\text { within } 3 \text { months of endoscopy, } n(\%)\end{array}$} & $25(30.5)$ \\
\hline \multicolumn{2}{|c|}{ NSAIDs within 3 months of endoscopy, $n(\%)$} & $8(9.8)$ \\
\hline
\end{tabular}

Fe Sat\%=Iron saturation \%; $\mathrm{Hb}=$ Hemoglobin; $\mathrm{MCV}=$ Mean Corpuscular Volume; SD=Standard Deviation 
Table 2: Significant findings on esophagogastroduodenoscopy in patients with anemia of chronic disease.

\begin{tabular}{|l|c|}
\hline \multicolumn{1}{|c|}{ Significant Findings } & Number $(\mathbf{n = 3 7 ,} \%)$ \\
\hline Gastric and/or duodenal erosions & $14(37.9)$ \\
\hline Peptic ulcer disease & $9(24.4)$ \\
\hline AVM & $5(13.3)$ \\
\hline Erosive esophagitis & $4(10.9)$ \\
\hline Hemorrhagic gastritis & $2(5.5)$ \\
\hline Portal gastropathy & $1(2.7)$ \\
\hline Large polyp >2 cm & $1(2.7)$ \\
\hline Gastric cancer & $1(2.7)$ \\
\hline
\end{tabular}

Significant findings=Arteriovenous Malformation (AVM); Erosive esophagitis of any grade; Hemorrhagic gastritis; Gastric and/or duodenal erosions; Cameron erosions; Malignancy; Peptic ulcer disease; Celiac disease, Gastric Antral Vascular Ectasia (GAVE); Portal gastropathy; Polyps $>2 \mathrm{~cm}$, and submucosal mass. Although not all were observed, these findings are considered known causes of anemia on EGD.

Table 3: Significant findings on colonoscopy in patients with anemia of chronic disease.

\begin{tabular}{|l|c|}
\hline \multicolumn{1}{|c|}{ Significant Findings } & Number $(\mathbf{n = 7 ,} \%)$ \\
\hline Polyp $>\mathbf{2} \mathbf{~ c m ~}$ & $3(42.8)$ \\
\hline Colorectal cancer & $2(28.6)$ \\
\hline Colo-ileal ulcers & $1(14.3)$ \\
\hline AVM & $1(14.3)$ \\
\hline
\end{tabular}

Significant findings=Polyp >2 cm; AVM; Colitis of any etiology including Inflammatory Bowel Disease (IBD); NSAIDs; Microscopic; Ischemic; Radiation or infectious colitis; lleal ulcers; Malignancy, and Colorectal ulcers. Although not all were observed, these findings are considered known causes of anemia on colonoscopy.

Table 4 reported the endoscopic yield for EGD and colonoscopy based on laboratory and clinical variables. Endoscopic yield for EGD was $50 \%$ in both $\mathrm{Hb} \leq 8 \mathrm{gm} / \mathrm{dl}$ and $>8 \mathrm{gm} / \mathrm{dl}(\mathrm{p}=1.00)$ and $40 \%$ and $57 \%$ for $\mathrm{MCV} \leq 85$ and $>85$, respectively $(\mathrm{p}=0.16$ ). Ferritin 101-499 $\mathrm{ng} / \mathrm{ml}$ and $\geq 500 \mathrm{ng} / \mathrm{ml}$ had endoscopic yield yields of $49 \%$ and $46 \%$, respectively $(\mathrm{p}=0.80)$. Endoscopic yield for EGD was $50 \%$ in both those on anticoagulants and/or antiplatelet agents within 3 months of endoscopy and those who were not $(\mathrm{p}=1.00)$, and endoscopic yield was $75 \%$ and $47 \%$ for those who were on NSAIDs and those who were not $(\mathrm{p}=0.26)$. Thus, none of the clinical or lab variables had an impact on endoscopic yield for EGD.

\section{Discussion and Conclusions}

Iron deficiency anemia is a well-established indication for endoscopic investigation. However, there are no guidelines regarding the role of endoscopy in evaluation of anemia of chronic disease. To our knowledge, this study is the first to evaluate yield for EGD and colonoscopy in patients who have ACD without GI symptoms and examine variables that may increase endoscopic yield in these patients. Prior studies reported endoscopic yields ranging from $8 \%$ to $41 \%$ for EGD and $6 \%$ to $37 \%$ for colonoscopy $[12-17,20]$. Our study found endoscopic yield to be above this range for EGD (50\%) and at the low end of the range for colonoscopy (11\%). The variations in defining significant findings for EGD and colonoscopy may explain the discrepancies among our study and others. Another possibility for discrepancies between our study and past studies may due to the patient populations. The VA population is heavily Caucasian males which
Table 4: Endoscopic yield for esophagogastroduodenoscopy and colonoscopy in patients with anemia of chronic disease.

\begin{tabular}{|c|c|c|c|c|c|}
\hline Variables & Value & EGD Yield (\%) & p & $\begin{array}{l}\text { Colonoscopy } \\
\text { Yield (\%) }\end{array}$ & p \\
\hline \multirow{2}{*}{$\mathrm{Hb}(\mathrm{gm} / \mathrm{dl})$} & $\leq 8$ & $11 / 22(50)$ & \multirow{2}{*}{1.00} & $1 / 17(6)$ & \multirow{2}{*}{0.75} \\
\hline & $>8$ & $26 / 52(50)$ & & $6 / 47$ (13) & \\
\hline \multirow{2}{*}{$\mathrm{MCV}(\mathrm{fL})$} & $\leq 85$ & $12 / 30(40)$ & \multirow{2}{*}{0.16} & $4 / 27(15)$ & \multirow{2}{*}{0.66} \\
\hline & $>85$ & $25 / 44(57)$ & & $3 / 37(8)$ & \\
\hline \multirow{2}{*}{ Ferritin (ng/ml) } & $101-499$ & $30 / 61$ (49) & \multirow{2}{*}{0.80} & $6 / 52(12)$ & \multirow{2}{*}{1.00} \\
\hline & $\geq 500$ & $6 / 13(46)$ & & $1 / 12(8)$ & \\
\hline \multirow{2}{*}{$\begin{array}{l}\text { Anticoagulants } \\
\text { and/or anti- } \\
\text { platelet agents }\end{array}$} & Yes & $11 / 22(50)$ & \multirow{2}{*}{1.00} & $4 / 16(25)$ & \multirow{2}{*}{0.11} \\
\hline & No & $26 / 52(50)$ & & $3 / 48(6)$ & \\
\hline \multirow{2}{*}{ NSAIDs } & Yes & $6 / 8(75)$ & \multirow{2}{*}{0.26} & $0 / 6(0)$ & \multirow{2}{*}{0.83} \\
\hline & No & $31 / 66$ (47) & & $7 / 58(11)$ & \\
\hline
\end{tabular}

may limit our studies application to the general public. Based upon laboratory analysis and the demographics of our study population, there was no significant statistical relationship of endoscopic findings and degree of anemia, ferritin level, MCV, and use of antiplatelet and/or anticoagulants or NSAIDs. Of note, the endoscopic yield of colonoscopies were lower compared to prior studies which may be due to the lower than expected number of colonoscopies performed for ACD.

Endoscopic yield for colonoscopy was $6 \%$ and $13 \%$ for $\mathrm{Hb} \leq 8 \mathrm{gm} /$ $\mathrm{dl}$ and $>8 \mathrm{gm} / \mathrm{dl}$, respectively ( $\mathrm{p}=0.75$ ), and $15 \%$ and $8 \%$ for MCV $\leq 85$ and $>85$, respectively $(\mathrm{p}=0.66)$. Endoscopic yield for colonoscopy was $12 \%$ and $8 \%$ for ferritin $101-499 \mathrm{ng} / \mathrm{ml}$ and $\geq 500 \mathrm{ng} / \mathrm{ml}$, respectively $(\mathrm{p}=1.00)$. Endoscopic yield for colonoscopy was $25 \%$ for those using anticoagulants and/or antiplatelet agents and $6 \%$ for those not using $(\mathrm{p}=0.11)$. Endoscopic yield was $0 \%$ and $11 \%$ in those who were using NSAIDs and those who were not $(\mathrm{p}=0.83)$. Consequently, as with EGD, none of the clinical or laboratory variables had an impact on endoscopic yield for colonoscopy.

Our study has several limitations. First, the study was conducted at a single medical facility.

Our largely homogeneous sample was predominantly older white male veterans.

Consequently, generalizability to other populations (e.g., younger ages and other races, females, and broader community settings) should be done with caution. Second, in retrospective chart reviews, data omissions are more likely and the accuracy of data collection may be more challenging. For example, approximately one-third of patients diagnosed with anemia did not have the serum ferritin lab necessary to determine if a patient had anemia of chronic disease. Third, because our facility followed stringent criteria to perform endoscopy on patients with anemia, our sample size was restricted. Further studies will need to be conducted to assess if underlying comorbidities such as age, obesity, tobacco use, and cause of anemia of chronic disease have any statistical significance in regards to endoscopic yield. Of note, there is limited data on endoscopic yield of VCE for ACD. Consideration should be taken to evaluate if there is a role of VCE for adequate evaluate of ACD.

Our study suggests that EGD is beneficial for evaluation of all patients with ACD without GI symptoms, regardless of underlying 
lab or clinical findings. The current standard of practice recommends complete endoscopic evaluation for patients with iron deficiency anemia only. However, there are no such recommendations for formal endoscopic investigation for patients that fall into the anemia of chronic disease. Given the endoscopic yield for EGDs in our study group that fit the criteria of anemia of chronic disease, there should be consideration if these patients would benefit from at least an EGD to assess the anemia. Often the endoscopic findings can be treated either endoscopically or which medication which may improve a patient's anemia. On the other, due to limited yield of colonoscopy in patients with ACD, colonoscopy should be performed on a caseby-case basis as the number of colonoscopies was low. Further largescale studies would be needed to investigate if patients with anemia of chronic disease could benefit from full endoscopic work up similar to patients with iron deficiency anemia. Large-scale prospective studies are needed to draw more definitive conclusions about the use of endoscopy in patients with anemia of chronic disease in the absence of GI symptoms and classic iron deficiency.

\section{Conflict of Interest}

The authors of this manuscript do not have any financial, consultant, or institutional conflicts of interests to disclose.

\section{References}

1. World Health Organization (2001) Archived: Iron deficiency anemia: Assessment, prevention and control: A guide for programme managers. Anaemia/iron deficiency, Nutrition, WHO.

2. Goddard AF, James MW, Mclntyre AS, Scott BB, British Society of Gastroenterology (2011) Guidelines for the management of iron deficiency anemia. Gut 60: 1309-1316.

3. Camaschella C (2015) Iron-deficiency anemia. N Engl J Med 372: 1832-1843.

4. Ioannou GN, Rockey DC, Bryson CL, Weiss NS (2002) Iron deficiency and gastrointestinal malignancy: A population-based cohort study. Am J Med 113: 276-280.

5. Weiss G, Goodnough LT (2005) Anemia of chronic disease. N Engl J Med 352: 1011-1023.

6. Bermejo F, García-López S (2009) A guide to diagnosis of iron deficiency and iron deficiency anemia in digestive diseases. World $J$ Gastroenterol 15: 4638-4643.

7. Longo D, Harrison TR (2013) Harrison's hematology and oncology. In: Longo D (eds) $2^{\text {nd }}$ Edition, McGraw-Hill Education, United Kingdom.
8. Wians FH Jr, Urban JE, Keffer JH, Kroft SH (2001) Discriminating between iron deficiency anemia and anemia of chronic disease using traditional indices of iron status vs. transferrin receptor concentration. Am J Clin Pathol 115: 112-118.

9. World Health Organization (2011) Serum ferritin concentrations for the assessment of iron status and iron deficiency in populations. World Health Organization.

10. Krause JR, Stolc $V(1979)$ Serum ferritin and bone marrow iron stores: Correlation with absence of iron in biopsy specimens. Am J Clin Pathol 72: 817-820.

11. DeLoughery TG (2014) Microcytic anemia. N Engl J Med 371: 13241331.

12. Milano A, Balatsinou C, Filippone A, Caldarella MP, Laterza F, et al. (2011) A prospective evaluation of iron deficiency anemia in the GI endoscopy setting: Role of standard endoscopy, videocapsule endoscopy, and CT-enteroclysis. Gastrointest Endosc 73: 1002-1008.

13. Jayadevan $R$, Joseph $P$, Aggarwal $P$, Kokkat $A$, Ricci $M$, et al. (2003) Diagnostic yield of upper endoscopy and colonoscopy in asymptomatic anemia. Gastroenterol 124: A356.

14. Majid S, Salih M, Wasaya R, Jafri W (2008) Predictors of gastrointestinal lesions on endoscopy in iron deficiency anemia without gastrointestinal symptoms. BMC Gastroenterol 8: 52.

15. Fireman Z, Gurevich V, Coscas D, Kopelman Y, Segal A, et al. (1999) Results of gastrointestinal evaluation in 90 hospitalized iron deficiency anemia patients. Isr Med Assoc J 1: 232-235.

16. Grassini M, Verna C, Niola P, Navino M, Battaglia E, et al. (2007) Appropriateness of colonoscopy: Diagnostic yield and safety in guidelines. World J Gastroenterol 13: 1816-1819.

17. Rockey DC, Cello JP (1993) Evaluation of the gastrointestinal tract in patients with iron-deficiency anemia. N Engl J Med 329: 1691-1695.

18. Tong J, Svarta S, Ou G, Kwok R, Law J, et al. (2012) Diagnostic yield of capsule endoscopy in the setting of iron deficiency anemia without evidence of gastrointestinal bleeding. Can J Gastroenterol 26: 687690.

19. Koulaouzidis A, Rondonotti E, Giannakou A, Plevris JN (2012) Diagnostic yield of small-bowel capsule endoscopy in patients with iron-deficiency anemia: A systematic review. Gastrointest Endosc 76: 983-992.

20. Powell N, McNair A (2008) Gastrointestinal evaluation of anemic patients without evidence of iron deficiency. Eur J Gastroenterol Hepatol 20: 1094-1100. 